\title{
Altered Epidermal Permeability Barrier Function in the Uninvolved Skin Supports a Role of Epidermal Dysfunction in the Pathogenesis of Occupational Hand Eczema
}

\author{
Xiaohua Wanga ${ }^{\mathrm{a}}$ Li Ye $^{\mathrm{a}}$ Qingsong Lai ${ }^{\mathrm{b}}$ Si Wen ${ }^{\mathrm{a}}$ Zijun Long ${ }^{\mathrm{a}}$ Xiaoyu Qiu ${ }^{\mathrm{a}}$ \\ Peter M. Elias ${ }^{c}$ Bin Yang ${ }^{a}$ Mao-Qiang Man ${ }^{\mathrm{a}}$ \\ ${ }^{a}$ Dermatology Hospital, Southern Medical University, Guangzhou, China; ${ }^{b}$ Center of Chronic Disease Prevention, \\ Puning City, China; ' Department of Dermatology, University of California San Francisco and Veterans Affairs Medical \\ Center, San Francisco, CA, USA
}

\section{Keywords}

Hand eczema $\cdot \mathrm{pH} \cdot$ Hydration $\cdot$ Permeability barrier .

Transepidermal water loss

\begin{abstract}
Although a compromised epidermal permeability barrier can contribute to the development of contact dermatitis, whether subjects with hand eczema display abnormalities in baseline epidermal permeability barrier function in their uninvolved skin remains unknown. The aim of the present study was to assess epidermal permeability barrier function in subjects with and without hand eczema in clothing manufacturers. Upon approval by the institutional review board, volunteers were recruited from clothing manufacturers in Guangzhou City, China. An 11-item questionnaire was used to collect general data from the volunteers. The diagnoses of self-proclaimed hand eczema were further confirmed by a dermatologist. Epidermal biophysical properties, including transepidermal water loss (TEWL) rates, stratum corneum hydration and skin surface $\mathrm{pH}$ were measured on the flexural surface of the left forearm in all volunteers. Epidermal biophysical properties were compared among cohorts of subjects with active hand eczema, a prior history of hand eczema and without any history of hand eczema. A total of 650
\end{abstract}

(c) 2020 S. Karger AG, Basel

\section{KARGER}

karger@karger.com

www.karger.com/spp questionnaires were collected from 462 females and 188 males, with a mean age of $36.7 \pm 0.46$ years (range 1669 years; $95 \% \mathrm{Cl} 35.8-37.59)$. Thirty-five subjects (5.4\%) currently had hand eczema, while 28 subjects (4.3\%) reported a prior history of hand eczema that was inactive currently. The prevalence of hand eczema did not differ significantly between genders. Neither a prior personal nor a family history of allergies was associated with the prevalence of hand eczema, but certain occupations and frequent contact with disinfectants were independently associated with the prevalence of hand eczema. In the overall cohort, males displayed higher TEWL rates and stratum corneum hydration levels than did females. Both skin surface $\mathrm{pH}$ and TEWL rates differed significantly among normal controls and subjects with active hand eczema or a prior history of hand eczema ( $p<$ 0.05). In conclusion, the uninvolved skin site of subjects with hand eczema exhibits abnormalities in epidermal permeability barrier, supporting a pathogenic role of epidermal dysfunction in hand eczema. Whether subjects with hand eczema in other occupations also display altered epidermal function on uninvolved skin remains to be explored.

(c) 2020 S. Karger AG, Basel

Xiaohua Wang and Li Ye contributed equally to this work.
Mao-Qiang Man, MD, or Bin Yang, MD

Dermatology Service (190)

4150 Clement Street

San Francisco, CA 94121 (USA)

mqman@ hotmail.com or yangbin101@ hotmail.com 


\section{Introduction}

Defects in the epidermal permeability barrier can provoke cutaneous inflammation [1]. Conversely, improvements in the epidermal permeability barrier can prevent and alleviate some inflammatory dermatoses. Studies showed that improvements in epidermal permeability barrier with a topical lipid mixture markedly improved the severity scoring of atopic dermatitis in children [2]. Likewise, topical applications of a barrier repair emollient in combination with topical glucocorticoid cream reduced psoriasis area severity index scores by approximately $25 \%$ in comparison to glucocorticoid cream alone [3]. Moreover, recent studies demonstrated that improvements in epidermal permeability barrier function delayed the relapse of psoriasis [4]. Furthermore, expression levels of proinflammatory cytokines in normal-appearing aged murine skin could also be lowered simply by improvements in epidermal permeability barrier function [5]. Together, disparate types of evidence suggest a regulatory role for the epidermal permeability barrier in the development of cutaneous inflammation.

Hand eczema, a common dermatosis, belongs to the category of contact dermatitis and it is often associated with particular occupations. Studies suggest that a defective epidermal permeability barrier function could contribute to the development of contact dermatitis. First, mutation in filaggrin, a structural protein required for the epidermal permeability barrier, decreases thresholds for both irritant and allergic contact dermatitis in mice [6]. Likewise, filaggrin mutations are associated with an enhanced tendency to develop both irritant and allergic contact dermatitis in humans $[7,8]$. Moreover, reductions in filaggrin content were found in lesional skin of hand eczema, supporting a possible role for the epidermal permeability barrier function in the pathogenesis of hand eczema [9]. Second, while deficiency in caspase $14 \mathrm{im}$ pairs the epidermal permeability barrier [10], the uninvolved skin of hand eczema subjects displays a lower expression of caspase 14 [11]. Third, deficiencies in late cornified envelope proteins, LCE3B and LCE3C, other structural proteins of the barrier, are associated with allergic contact dermatitis [12].

Collectively, these studies suggest a pathogenic role for defects in the epidermal permeability barrier in the development of hand eczema. However, there is still a lack of sufficient, direct evidence to support that a defective permeability barrier predisposes to the development of hand eczema. If the development of hand eczema is attributed to the defective epidermal permeability barrier, unin- volved skin sites should exhibit elevations in transepidermal water loss (TEWL) rates, an indicator of permeability status. Therefore, we compared here the epidermal permeability barrier function in a large cohort with or without hand eczema.

\section{Subjects and Methods}

This study was carried out in clothing manufacturer workers in Guangzhou City during the months of November and December. An 11-item questionnaire was used to collect general information of volunteers (online suppl. Table 1; for all online suppl. material, see www.karger.com/doi/10.1159/000506425). This questionnaire focused primarily on work-related questions. Subjects with selfproclaimed hand eczema were further examined by a dermatologist, who confirmed the diagnosis of hand eczema, according to its clinical features. No effort was made to distinguish between allergic and irritant contact dermatitis. Except for regular bathing and washing, no moisturizer lotion or cream was applied to measurement sites for at least $24 \mathrm{~h}$ prior to measurements. Epidermal biophysical properties, including TEWL rates and stratum corneum hydration were measured with GPskin Barrier ${ }^{\circledR}$ (GPower Inc., Seoul, South Korea) [13], while skin surface $\mathrm{pH}$ was measured with a portable skin $\mathrm{pH}$ meter (Hanna Instruments, Smithfield, RI, USA) on the flexor side of the left forearm. This study was approved by the institutional review board of the Dermatology Hospital of Southern Medical University (GDDHLS20180505). Informed consents were obtained from all subjects prior to the study.

\section{Statistics}

GraphPad Prism 5 software was used for all statistical analyses. The two-sided Fisher's exact test or $\chi^{2}$ test was used when comparing qualitative variables. The Mann-Whitney test was used to determine the significance between groups, while one-way ANOVA was used to determine significances among more than two groups. Data are expressed as means \pm SEM. $p$ values are indicated in tables, the figure or figure legend.

\section{Results}

\section{Basic Characteristics of Subjects}

A total of 650 questionnaires were obtained from 462 females and 188 males, with a mean age of $36.7 \pm 0.46$ years (range: 16-69 years; 95\% CI: 35.8-37.59). Subjects with current hand eczema were $38.69 \pm 1.90$ years of age (median: 40; 95\% CI: 34.83-42.54) while subjects with past hand eczema (not now) were $36.61 \pm 2.17$ years of age (median: 35; 95\% CI: 32.16-41.06). A majority of these volunteers $(73 \%)$ worked in the production line. Over $80 \%$ of subjects in these cohorts did neither routinely use detergents to wash their hands nor moisturizers after hand washing. Fifty-five (8\%) subjects had a family history of allergy, while $29 \%$ of subjects had a personal his- 
Table 1. Demographic characteristics of subjects

\begin{tabular}{|c|c|c|}
\hline & Females $(n=462)$ & Males $(n=188)$ \\
\hline Mean age \pm SEM (median, range), years & $36.86 \pm 0.84(35,17-67)$ & $36.63 \pm 0.54(37,16-69)$ \\
\hline Hand eczema at present time & $26(6)$ & $9(5)$ \\
\hline History of hand eczema, but not currently & $19(4)$ & $9(5)$ \\
\hline Other dermatitis (excluding hand eczema and psoriasis) & 0 & 0 \\
\hline \multicolumn{3}{|l|}{ Occupation } \\
\hline Production lines & $337(73)$ & $137(73)$ \\
\hline Warehouse workers & $14(3)$ & $9(5)$ \\
\hline Management & $3(1)$ & $1(1)$ \\
\hline Others & $108(23)$ & $41(22)$ \\
\hline \multicolumn{3}{|l|}{ Substances that your hands frequently contact } \\
\hline Disinfectants & $6(1)$ & $1(1)$ \\
\hline Detergents & $96(21)$ & $17(9)^{\mathrm{b}}$ \\
\hline Hair dye products & 1 & 0 \\
\hline Cosmetics & $16(3)$ & 0 \\
\hline Lubricants & $20(4)$ & $14(7)$ \\
\hline Others & $7(2)$ & $6(3)$ \\
\hline Wet work & $5(1)$ & $6(3)$ \\
\hline \multicolumn{3}{|l|}{ Washing hands } \\
\hline Mean frequency \pm SEM, times/day & $7 \pm 0.16$ & $7 \pm 0.46$ \\
\hline Washing with detergents & $31(7)$ & $24(13)^{\mathrm{d}}$ \\
\hline \multicolumn{3}{|l|}{ Using moisturizers after washing hands } \\
\hline Most times & $24(5)$ & $0^{\mathrm{a}}$ \\
\hline Occasionally & $97(21)$ & $7(4)^{\mathrm{c}}$ \\
\hline Never & $341(74)$ & $181(96)^{\mathrm{c}}$ \\
\hline A personal history of allergy/atopic dermatitis & $131(28)$ & $55(29)$ \\
\hline A family history of allergy/atopic dermatitis & $39(8)$ & $16(9)$ \\
\hline
\end{tabular}

Results are given as numbers with percentages in parentheses unless indicated otherwise. The two-sided $\chi^{2}$ test was used to assess the significant differences between genders. ${ }^{\mathrm{a}} p=0.0018,{ }^{\mathrm{b}} p=0.0003,{ }^{\mathrm{c}} p<0.0001,{ }^{\mathrm{d}} p=$ 0.0119 .

tory of allergy. Thirty-five subjects (5.4\%) currently had hand eczema while 28 subjects $(4.3 \%)$ only had a prior history of, but no current, hand eczema. Lifetime prevalence of hand eczema was 9.7\% (63/650). Prevalence of hand eczema did not differ significantly between genders in this cohort although female dominance has been documented $[3,14]$. Characteristics of these cohorts are summarized in Table 1.

\section{Occupation Dominates the Prevalence of Hand Eczema}

Because routine occupational and/or household activities are often associated with the development of hand eczema, we first analyzed which of these activities are possible risk factors for hand eczema. The prevalence of hand eczema varied greatly with occupation $(p<0.0001$, Table 2 ). Subjects working either at a production line or warehouse appeared to be at a higher risk for the development of hand eczema in comparison to other occupations (Table 2).

The prevalence of hand eczema varied greatly with exogenous substances or materials that hands frequently contacted ( $p=0.0408$ ). Among the substances and materials, disinfectants were most strongly associated with hand eczema (relative risk $=0.1727, p<0.05$; Table 2). Although wet work is considered as a major contributor to hand eczema [15], the prevalence of hand eczema did not differ significantly between wet and nonwet workers in this study. Likewise, the frequency of daily washing hands did not influence the development of hand eczema. Subjects with hand eczema washed their hands $7.9 \pm 0.7$ times per day (median: 7; 95\% CI: 6.40225-9.42632) while subjects without hand eczema washed their hands $7.2 \pm$ 0.2 times per day (median: 7; 95\% CI: 6.85185-7.59789). Finally, the prevalence of hand eczema was comparable in subjects with or without a prior or family history of al- 
Table 2. Possible risk factors of hand eczema

\begin{tabular}{|c|c|c|c|}
\hline Factors & $N$ & $\begin{array}{l}\text { Hand eczema, } \\
n(\%)\end{array}$ & $p$ value (odds ratio, 95\% CI) \\
\hline \multicolumn{4}{|l|}{ Occupation } \\
\hline Production & 474 & $27(5.7)$ & $0.0059(0.1119,0.01506-0.8307)$ \\
\hline Services & 23 & $7(30.4)$ & $<0.0001(0.01802,0.002038-0.1593)$ \\
\hline Management & 4 & 0 & \\
\hline Others & 149 & $1(0.7)$ & \\
\hline \multicolumn{4}{|c|}{ Substances and materials that your hands frequently contact } \\
\hline Disinfectants & 7 & $2(28.6)$ & $0.0479(0.1298,0.02388-0.7055)$ \\
\hline Detergents & 113 & $6(5.3)$ & \\
\hline Hair dye products & 1 & 0 & \\
\hline Cosmetics & 16 & 0 & \\
\hline Lubricants & 34 & $3(8.8)$ & \\
\hline Others & 13 & $1(7.7)$ & \\
\hline None of these & 466 & $23(4.9)$ & \\
\hline \multicolumn{4}{|l|}{ Wet work (ns) } \\
\hline Yes & 11 & $1(9.1)$ & \\
\hline No & 639 & $34(5.3)$ & \\
\hline \multicolumn{4}{|l|}{ Frequency of washing hands (ns) } \\
\hline$\geq 10$ times/day & 133 & $7(5.3)$ & \\
\hline$<10$ times/day & 517 & $28(5.4)$ & \\
\hline \multicolumn{4}{|l|}{ Washing hands with detergents (ns) } \\
\hline Yes & 55 & $2(3.6)$ & \\
\hline No & 595 & $33(5.5)$ & \\
\hline \multicolumn{4}{|c|}{ Using moisturizers after washing hands (ns) } \\
\hline Most times & 24 & $1(4.2)$ & \\
\hline Occasionally & 104 & $7(6.7)$ & \\
\hline Never & 522 & $27(5.2)$ & \\
\hline \multicolumn{4}{|l|}{ History of allergy/atopic dermatitis (ns) } \\
\hline $\begin{array}{l}\text { Neither personal nor family history of } \\
\text { allergy }\end{array}$ & 444 & $21(4.7)$ & \\
\hline Only a personal history of allergy & 151 & $12(7.9)$ & \\
\hline Only a family history of allergy & 20 & $1(5)$ & \\
\hline $\begin{array}{l}\text { Both personal and family history of } \\
\text { allergy }\end{array}$ & 35 & $1(2.9)$ & \\
\hline
\end{tabular}

Two-sided Fisher's exact test was used to assess the significant differences. ns, not significant.

lergies (Table 2). Taken together, only occupation and materials that frequently contact hands appear to be risk factors for hand eczema in this occupational setting.

\section{Uninvolved Skin Site of Subjects with Hand Eczema}

Displays Compromised Permeability Barrier Function

Previous studies have shown that a defective permeability barrier can enhance the percutaneous penetration of substances into the skin, predisposing to the development of contact dermatitis [16]. We next assessed the epidermal permeability barrier function in these subjects. In agreement with previous findings [17], males exhibited higher basal TEWL rates in comparison to females
(Fig. 1a). Similarly, stratum corneum hydration levels in males were also significantly higher than those in females (Fig. 1a, $p<0.0001$ ). Moreover, TEWL rates were significantly higher in subjects with current and a prior history of hand eczema altogether than in subjects without hand eczema (Fig. 1b, $p<0.01$ ). Although skin surface $\mathrm{pH}$ did not differ significantly either between subjects with current and a prior history of hand eczema altogether, and subjects without hand eczema (Fig. 1b), subjects with active hand eczema displayed higher skin surface $\mathrm{pH}$ in comparison to subjects with either a prior history of hand eczema $(\mathrm{q}=5.029, p<0.01)$ or without a history of hand eczema (Fig. $1 c, q=6.09, p<0.001$ ). Stratum corneum 


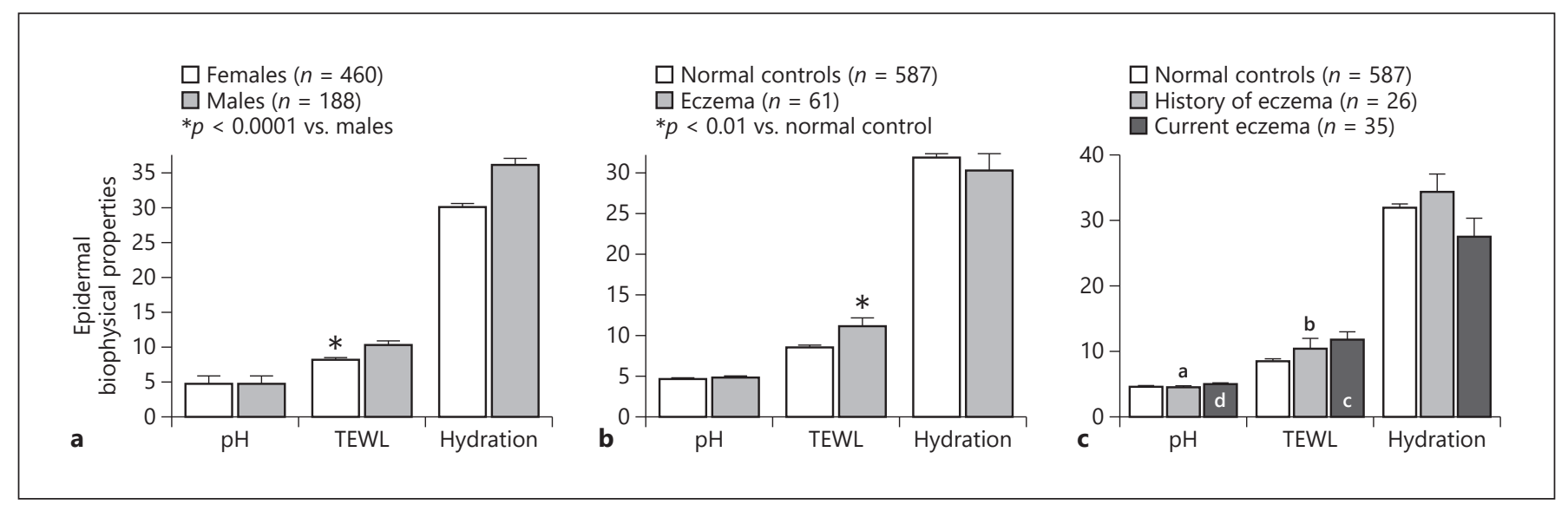

Fig. 1. Comparison of epidermal function in subjects with and without hand eczema. a Comparison of epidermal function between males and females in this cohort. Because of nonnormality of the data, an unpaired $t$ test (Mann-Whitney test) was used for comparisons between the two groups. $\mathbf{b}$ Comparison of epidermal function between subjects without hand eczema and subjects with either current or a prior history of eczema. Because of nonnormality of the data, an unpaired $t$ test (Mann-Whitney test) was used for comparisons between the two groups. c Comparison of epidermal function among subjects without hand eczema, with current

hydration levels were $14 \%$ lower in subjects with active hand eczema than those without hand eczema (Fig. 1c, $27.46 \pm 2.85$ vs. $31.94 \pm 0.52, p=0.0635$ ). Striking differences were found in TEWL rates among subjects without a history of hand eczema, with active or a prior history of hand eczema (Fig. $1 c, F=5.806, p=0.0032$ ). Furthermore, in subjects currently without active hand eczema but a prior history of hand eczema, their TEWL rates were $18 \%$ higher than in those without a history of hand eczema at all ( $10.42 \pm 1.55$ vs. $8.56 \pm 0.24)$. Finally, subjects with and without a family history of hand eczema or allergy displayed comparable levels of TEWL, stratum corneum hydration and skin surface $\mathrm{pH}$. These results demonstrate that subjects with hand eczema exhibit defects in epidermal permeability barrier and stratum corneum acidity on the involved skin site.

\section{Discussion}

While hand eczema is a common dermatosis in the USA and Europe, information about the prevalence of hand eczema in China is limited. We show here that the lifetime prevalence of hand eczema was $9.7 \%$, while point prevalence was $5.4 \%$ in this cohort, which both were low- eczema or those with a history of eczema. Data are expressed as means \pm SEM. A Kruskal-Wallis test was used to determine the significant differences among groups, and the differences between hand eczema and normal controls were determined using one-way ANOVA with post hoc Dunnett's multiple comparison test. $p$ values above the columns vary significantly between groups $\left({ }^{\mathrm{a}} p<0.05\right.$ and ${ }^{\mathrm{b}} p<0.01$ ) while $p$ values in the columns are versus subjects without hand eczema ( ${ }^{\mathrm{c}} p<0.01$ and $\left.{ }^{\mathrm{d}} p<0.001\right) . n=61$ for hand eczema and $n=587$ for subjects without hand eczema.

er than that reported in European populations [14]. Although no efforts were made to differentiate allergic from irritant contact dermatitis, hand eczema in this cohort likely was, at least to a large extent, irritant contact dermatitis because (1) the majority of occupational hand eczemas are irritant rather than allergic contact dermatitis $[15,18]$ and (2) the prevalence of hand eczema was comparable in subjects with and without a history of allergies.

Regarding risk factors, many factors can contribute to the development of hand eczema. Occupational wet work and frequent hand washing have been considered as major contributors to hand eczema at least in the health care industry $[18,19]$. However, the present study did not reveal any link between hand eczema and either wet work or frequent hand washing. The discrepant results between the present study and others could be due to the relatively small sample size in the present study, where there were only 13 wet workers. Regarding a possible link between atopic dermatitis and hand eczema, it is inconclusive. While subjects with atopic dermatitis display a higher prevalence of hand eczema compared to those without atopic dermatitis [20], the rates of allergic contact dermatitis on the hands were comparable between atopic and nonatopic subjects [21]. Moreover, it is no surprise that no subjects with atopic dermatitis were present in
Wang/Ye/Lai/Wen/Long/Qiu/Elias/Yang/ Man 
this cohort, possibly because of the low overall prevalence of adult atopic dermatitis $(<\% 1)$ in China [22]. The link between topical use of disinfectant and hand eczema is also uncertain. While previous studies showed no association of disinfectants with hand eczema, the present study demonstrated that over $28 \%(2 / 7)$ of subjects with hand eczema frequently contacted disinfectants, but our sample size was too small to draw any conclusions. That occupation markedly influenced the prevalence of hand eczema is consistent with prior observations [19]. In this cohort, subjects working in production lines and warehouses exhibited the highest risk for hand eczema, possibly because they repeatedly contact the same or similar substance(s) daily. In such cases, occasional contact with substances at low concentration may not be harmful, but repeated contact could eventually provoke hand eczema. Finally, other studies have shown that single nucleotide polymorphisms of inflammation-related genes are associated with hand eczema [23]. Whether such genes were altered in these subjects is unknown.

A pathogenic role for a defective epidermal permeability barrier in hand eczema has long been proposed, because (1) expression levels of barrier-related proteins, including filaggrin and caspase 14, decline in the lesional skin of hand eczema $[9,11]$, (2) TEWL rates increase in lesional skin and adjacent nonlesional skin [11], (3) topical barrier repair strategies delay the relapses of and/or improve hand eczema $[24,25]$ and (4) skin disorders, such as atopic dermatitis, with a defective permeability barrier are risk factors of hand eczema [26]. However, direct evidence to support the role of epidermal permeability dysfunction in hand eczema is far less sufficient. In most, if not in all studies, measurements of TEWL rates were performed on lesional or their adjacent sites. Here, we showed that TEWL rates also elevated in the uninvolved skin sites of subjects with hand eczema, but the underlying mechanisms are unclear. Although filaggrin mutations, a presumed cause of barrier dysfunction, are associated with hand eczema, particularly irritant contact dermatitis $[27,28]$, the following evidence does not support a role of filaggrin mutations in the elevated TEWL rates in the present cohort: (a) not all hand eczema has been associated with filaggrin mutations, while environmental factors largely account for the development of hand eczema $[29,30]$; (b) humans with and without filaggrin mutation display comparable basal barrier function [31,32]; and (c) in mice with filaggrin mutations, elevations in TEWL rates were observed only in aged, but not young mice [6], while our subjects were under 40 years of age. Therefore, filaggrin mutations

Pathogenic Role of Epidermal Function in Hand Eczema likely did not contribute to the increased TEWL rates in this cohort. Nonetheless, doubtlessly elevated TEWL rates play a significant role in the pathogenesis of hand eczema. A number of previous studies have shown that disruption of the epidermal permeability barrier not only induces production and release of proinflammatory cytokines [1,33], but also stimulates T-cell proliferation [32], leading to reductions in thresholds of response to external stimuli [34]. Whereas hand eczema belongs to the category of contact dermatitis, results of the present study support the notion that pre-existing dysfunction of the epidermal permeability barrier predisposes to the development of hand eczema. Although the skin surface $\mathrm{pH}$ in subjects with hand eczema was significantly higher than that in subjects without hand eczema, it still falls within a normal range. Thus, the marginal elevation in skin surface $\mathrm{pH}$ likely did not contribute to the development of hand eczema.

Prior studies have demonstrated the importance of measuring epidermal permeability barrier function in evaluating the status and therapeutic efficacy of certain dermatoses. In both adults and children with atopic dermatitis, TEWL rates positively correlate with disease severity [35-37]. Moreover, measurement of TEWL rates is a reliable approach to evaluate the therapeutic efficacy of the treatments for both atopic dermatitis and psoriasis $[2$, $3,38]$. In addition, infants with higher TEWL rates during the first week of life predict a higher risk of atopic dermatitis later in the life independently of filaggrin mutations [39]. Likewise, TEWL rates predict the relapse of psoriasis, i.e., psoriasis relapses sooner in subjects with higher TEWL rates [4]. We showed here that uninvolved skin sites of subjects with hand eczema displayed higher TEWL rates, suggesting that TEWL rates could possibly serve as a proxy in predicting the risk of developing hand eczema, a notion which requires further studies. Notably, the TEWL rates were $2 \mathrm{~g} / \mathrm{m}^{2} / \mathrm{h}$ higher in males than in females in this cohort. However, we did not observe the difference in the prevalence of hand eczema between males and females, probably because males and females commonly have different occupations, which can influence the development of eczema. However, whether the gender differences in TEWL rates can contribute to the different prevalences of hand eczema between males and females remains to be determined, ideally in a large cohort that both males and females have the same or similar occupation.

In conclusion, the uninvolved skin sites of patients with hand eczema exhibit defects in epidermal permeability barrier function, which could contribute to the de- 
velopment of hand eczema. Conversely, improvements in the epidermal permeability barrier could prevent and/or treat hand eczema.

\section{Limitations}

There are several limitations in the present study, including (a) data using questionnaires to obtain participants' history of skin disorders may not be accurate, (b) whether and how much prior and/or current skin disorders contribute to the development of hand eczema remains to be determined and (c) because of the low prevalence of hand eczema, studies in large cohorts are required to confirm the results of the present study.

\section{Statement of Ethics}

This work was reviewed and approved by the Institutional Review Board of Dermatology Hospital (Approval No. GDDHLS20180505).

\section{Disclosure Statement}

All authors declare no conflicts of interest.

\section{Funding Sources}

This work was supported in part by the China National Natural Science Foundation (NSFC 81903188, LY), with resources from the Research Service, Department of Veterans Affairs Medical Center, San Francisco, CA, USA.

\section{Author Contributions}

Wang X., Ye L., Lai Q., Wen S., Long Z. and Qiu X. performed experiments. Man M.-Q. and Yang B. designed experiments. Man M.-Q. analyzed and interpreted data, and wrote the draft. Elias P.M. and Yang B. interpreted data and critically reviewed the paper.

\section{References}

1 Elias PM, Wood LC, Feingold KR. Epidermal pathogenesis of inflammatory dermatoses. Am J Contact Dermat. 1999 Sep;10(3):11926.

2 Chamlin SL, Kao J, Frieden IJ, Sheu MY, Fowler AJ, Fluhr JW, et al. Ceramide-dominant barrier repair lipids alleviate childhood atopic dermatitis: changes in barrier function provide a sensitive indicator of disease activity. J Am Acad Dermatol. 2002 Aug;47(2): 198-208.

3 Liu M, Li X, Chen XY, Xue F, Zheng J. Topical application of a linoleic acid-ceramide containing moisturizer exhibit therapeutic and preventive benefits for psoriasis vulgaris: a randomized controlled trial. Dermatol Ther (Heidelb). 2015 Nov-Dec;28(6):373-82.

4 Man MQ, Ye L, Hu L, Jeong S, Elias PM, Lv C. Improvements in epidermal function prevent relapse of psoriasis: a self-controlled study. Clin Exp Dermatol. 2019 Aug;44(6): 654-7.

5 Hu L, Mauro TM, Dang E, Man G, Zhang J, Lee D, et al. Epidermal Dysfunction Leads to an Age-Associated Increase in Levels of Serum Inflammatory Cytokines. J Invest Dermatol. 2017 Jun;137(6):1277-85.

6 Scharschmidt TC, Man MQ, Hatano Y, Crumrine D, Gunathilake R, Sundberg JP, et al. Filaggrin deficiency confers a paracellular barrier abnormality that reduces inflammatory thresholds to irritants and haptens. J Allergy Clin Immunol. 2009;124:496-506. e1-6.
7 de Jongh CM, Khrenova L, Verberk MM, Calkoen F, van Dijk FJ, Voss H, et al. Loss-offunction polymorphisms in the filaggrin gene are associated with an increased susceptibility to chronic irritant contact dermatitis: a casecontrol study. Br J Dermatol. 2008 Sep;159(3): 621-7.

8 Molin S, Vollmer S, Weiss EH, Ruzicka T, Prinz JC. Filaggrin mutations may confer susceptibility to chronic hand eczema characterized by combined allergic and irritant contact dermatitis. Br J Dermatol. 2009 Oct;161(4): 801-7.

9 Molin S, Merl J, Dietrich KA, Regauer M, Flaig M, Letulé V, et al. The hand eczema proteome: imbalance of epidermal barrier proteins. Br J Dermatol. 2015 Apr;172(4):9941001.

10 Denecker G, Hoste E, Gilbert B, Hochepied T, Ovaere $\mathrm{P}$, Lippens $\mathrm{S}$, et al. Caspase- 14 protects against epidermal UVB photodamage and water loss. Nat Cell Biol. 2007 Jun;9(6):666-74.

11 Wang B, Liu LL, Zhao ZT, Tu P. Impaired Skin Barrier Function and Downregulated Expression of Caspase-14 in Moderate to Severe Chronic Hand Eczema. Dermatology. 2018;234(5-6):180-5.

12 Molin S, Vollmer S, Weiss EH, Weisenseel P, Ruzicka T, Prinz JC. Deletion of the late cornified envelope genes LCE3B and LCE3C may promote chronic hand eczema with allergic contact dermatitis. J Investig Allergol Clin Immunol. 2011;21(6):472-9.
13 Ye L, Wang Z, Li Z, Lv C, Man MQ. Validation of GPSkin Barrier ${ }^{\circledR}$ for assessing epidermal permeability barrier function and stratum corneum hydration in humans. Skin Res Technol. 2019 Jan;25(1):25-9.

14 Behroozy A, Keegel TG. Wet-work Exposure: A Main Risk Factor for Occupational Hand Dermatitis. Saf Health Work. 2014 Dec;5(4): 175-80.

15 Johannisson A, Pontén A, Svensson Å. Prevalence, incidence and predictive factors for hand eczema in young adults - a follow-up study. BMC Dermatol. 2013 Oct;13(1):14.

16 Darlenski R, Kazandjieva J, Tsankov N, Fluhr JW. Acute irritant threshold correlates with barrier function, skin hydration and contact hypersensitivity in atopic dermatitis and rosacea. Exp Dermatol. 2013 Nov;22(11):752-3.

17 Mehta HH, Nikam VV, Jaiswal CR, Mehta HB. A cross-sectional study of variations in the biophysical parameters of skin among healthy volunteers. Indian J Dermatol Venereol Leprol. 2018 Jul-Aug;84(4):521.

18 Mekonnen TH, Yenealem DG, Tolosa BM. Self-report occupational-related contact dermatitis: prevalence and risk factors among healthcare workers in Gondar town, Northwest Ethiopia, 2018-a cross-sectional study. Environ Health Prev Med. 2019 Feb;24(1):11.

19 Hamnerius N, Svedman C, Bergendorff O, Björk J, Bruze M, Pontén A. Wet work exposure and hand eczema among healthcare workers: a cross-sectional study. Br J Dermatol. 2018 Feb;178(2):452-61.

20 Coenraads PJ. Hand eczema. N Engl J Med. 2012 Nov;367(19):1829-37. 
21 Coenraads PJ, Diepgen TL. Risk for hand eczema in employees with past or present atopic dermatitis. Int Arch Occup Environ Health. $1998 \mathrm{Feb} ; 71(1): 7-13$.

22 Nutten S. Atopic dermatitis: global epidemiology and risk factors. Ann Nutr Metab. 2015; 66 Suppl 1:8-16.

23 Yucesoy B, Talzhanov Y, Michael Barmada M, Johnson VJ, Kashon ML, Baron E, et al. Association of MHC region SNPs with irritant susceptibility in healthcare workers. J Immunotoxicol. 2016 Sep;13(5):738-44.

24 Lodén M, Wirén K, Smerud K, Meland N, Hønnås $H$, Mørk G, et al. Treatment with a barrier-strengthening moisturizer prevents relapse of hand-eczema. An open, randomized, prospective, parallel group study. Acta Derm Venereol. 2010 Nov;90(6):602-6.

25 Jordan L. Efficacy of a Hand Regimen in Skin Barrier Protection in Individuals With Occupational Irritant Contact Dermatitis. J Drugs Dermatol. 2016 Nov; 15(11):s81-5.

26 Ruff SM, Engebretsen KA, Zachariae C, Johansen JD, Silverberg JI, Egeberg A, et al. The association between atopic dermatitis and hand eczema: a systematic review and metaanalysis. Br J Dermatol. 2018 Apr;178(4): 879-88.

27 Handa S, Khullar G, Pal A, Kamboj P, De D. Filaggrin gene mutations in hand eczema patients in the Indian subcontinent: A prospective case-control study. Contact Dermat. 2019 Jun;80(6):359-64.
28 Landeck L, Visser M, Kezic S, John SM. Genotype-phenotype associations in filaggrin loss-of-function mutation carriers. Contact Dermat. 2013 Mar;68(3):149-55.

29 Lerbaek A, Bisgaard H, Agner T, Ohm Kyvik $\mathrm{K}$, Palmer CN, Menné T. Filaggrin null alleles are not associated with hand eczema or contact allergy. Br J Dermatol. 2007 Dec;157(6): 1199-204.

30 Lerbaek A, Kyvik KO, Mortensen J, Bryld LE, Menné T, Agner T. Heritability of hand eczema is not explained by comorbidity with atopic dermatitis. J Invest Dermatol. 2007 Jul; 127(7):1632-40.

31 Angelova-Fischer I, Mannheimer AC, Hinder A, Ruether A, Franke A, Neubert RH, et al. Distinct barrier integrity phenotypes in filaggrin-related atopic eczema following sequential tape stripping and lipid profiling. Exp Dermatol. 2011 Apr;20(4):351-6.

32 Jungersted JM, Scheer H, Mempel M, Baurecht $\mathrm{H}$, Cifuentes L, Høgh JK, et al. Stratum corneum lipids, skin barrier function and filaggrin mutations in patients with atopic eczema. Allergy. 2010 Jul;65(7):911-8.

33 Wood LC, Elias PM, Calhoun C, Tsai JC, Grunfeld C, Feingold KR. Barrier disruption stimulates interleukin-1 alpha expression and release from a pre-formed pool in murine epidermis. J Invest Dermatol. 1996 Mar;106(3):397-403.

34 Nishijima T, Tokura Y, Imokawa G, Seo N, Furukawa F, Takigawa M. Altered permeability and disordered cutaneous immunoregula- tory function in mice with acute barrier disruption. J Invest Dermatol. 1997 Aug;109(2): $175-82$.

35 Gupta J, Grube E, Ericksen MB, Stevenson MD, Lucky AW, Sheth AP, et al. Intrinsically defective skin barrier function in children with atopic dermatitis correlates with disease severity. J Allergy Clin Immunol. 2008 Mar; 121(3):725-730.e2.

36 Kim DW, Park JY, Na GY, Lee SJ, Lee WJ. Correlation of clinical features and skin barrier function in adolescent and adult patients with atopic dermatitis. Int J Dermatol. 2006 Jun;45(6):698-701.

37 Sugarman JL, Fluhr JW, Fowler AJ, Bruckner T, Diepgen TL, Williams ML. The objective severity assessment of atopic dermatitis score: an objective measure using permeability barrier function and stratum corneum hydration with computer-assisted estimates for extent of disease. Arch Dermatol. 2003 Nov;139(11):1417-22.

38 Darlenski R, Hristakieva E, Aydin U, Gancheva D, Gancheva T, Zheleva A, et al. Epidermal barrier and oxidative stress parameters improve during in $311 \mathrm{~nm}$ narrow band UVB phototherapy of plaque type psoriasis. J Dermatol Sci. 2018 Jul;91(1):28-34.

39 Horimukai K, Morita K, Narita M, Kondo M, Kabashima S, Inoue E, et al. Transepidermal water loss measurement during infancy can predict the subsequent development of atopic dermatitis regardless of filaggrin mutations. Allergol Int. 2016 Jan;65(1):103-8. 